\title{
Irreversible plasma and muscle protein oxidation and physical exercise
}

\section{Giulia Gorini, Tania Gamberi, Tania Fiaschi, Michele Mannelli, Alessandra Modesti \& Francesca Magherini}

To cite this article: Giulia Gorini, Tania Gamberi, Tania Fiaschi, Michele Mannelli, Alessandra Modesti \& Francesca Magherini (2018): Irreversible plasma and muscle protein oxidation and physical exercise, Free Radical Research, DOI: 10.1080/10715762.2018.1542141

To link to this article: https://doi.org/10.1080/10715762.2018.1542141

曲 Published online: 04 Dec 2018.

Submit your article to this journal ¿

山 Article views: 54

View Crossmark data ¿ 


\title{
Irreversible plasma and muscle protein oxidation and physical exercise
}

\author{
Giulia Gorini, Tania Gamberi, Tania Fiaschi, Michele Mannelli, Alessandra Modesti and Francesca Magherini \\ Department of Biomedical, Experimental and Clinical Sciences "Mario Serio", University of Florence, Florence, Italy
}

\begin{abstract}
The imbalance between the reactive oxygen (ROS) and nitrogen (RNS) species production and their handling by the antioxidant machinery (low molecular weight antioxidant molecules and antioxidant enzymes), also known as oxidative stress, is a condition caused by physiological and pathological processes. Moreover, oxidative stress may be due to an overproduction of free radicals during physical exercise. Excess of radical species leads to the modification of molecules, such as proteins - the most susceptible to oxidative modification - lipids and DNA. With regard to the oxidation of proteins, carbonylation is an oxidative modification that has been widely described. Several studies have detected changes in the total amount of protein carbonyls following different types of physical exercise, but only few of these identified the specific amino acidic residues targets of such oxidation. In this respect, proteomic approaches allow to identify the proteins susceptible to carbonylation and in many cases, it is also possible to identify the specific protein carbonylation sites. This review focuses on the role of protein oxidation, and specifically carbonyl formation, for plasma and skeletal muscle proteins, following different types of physical exercise performed at different intensities. Furthermore, we focused on the proteomic strategies used to identify the specific protein targets of carbonylation. Overall, our analysis suggests that regular physical activity promotes a protection against protein carbonylation, due to the activation of the antioxidant defence or of the turnover of protein carbonyls. However, we can conclude that from the comprehensive bibliography analysed, there is no clearly defined specific physiological role about this post-translational modification of proteins.
\end{abstract}

ARTICLE HISTORY

Received 10 April 2018

Revised 24 October 2018

Accepted 24 October 2018

\section{KEYWORDS}

Physical exercise; plasma; protein carbonylation; proteomics; skeletal muscle

\section{Introduction}

Protein carbonylation is an irreversible oxidative modification on specific amino acids caused by several factors. These include physiological processes, such as aging and physical exercise, and pathological processes, such as Alzheimer's disease, Parkinson's disease, cancer, diabetes, and sepsis [1-3]. Carbonyl derivatives can be formed through a direct metal catalysed oxidation (MCO) of the side chains of proline, arginine, lysine, and threonine and through oxidative cleavage of peptide bonds, and this is called "primary protein carbonylation." In addition, carbonyl derivatives can result from an indirect reaction of primary amino-groups of lysine with reduced sugar or their oxidation product and by a Michael addiction reaction of lysine, cysteine and histidine with $\alpha, \beta$ unsaturated aldehydes formed during peroxidation of polyunsaturated fatty acids. The most important products of the carbonylation reaction are aminoadipic semialdehyde from lysine, and glutamic semialdehyde from arginine and proline $[4,5]$.
Because of carbonylation, proteins result inactivated and ready for the proteasome-dependent degradation. On the other hand, it has been recently hypothesized that primary protein carbonylation is a reversible modification so that protein carbonyls may undergo "protein de-carbonylation" through a thiol-dependent reduction. This could suggest that protein carbonylation and decarbonylation may be involved in cell signalling pathways [6].

Several studies have detected changes in the total amount of protein carbonylation following different types of physical exercise, but only few of these identified the specific proteins more sensitive to oxidation. Proteomic approaches can give the appropriate name to the proteins subjected to carbonylation and identify the specific amino acids susceptible to this modification. This peculiar aspect of the proteomic studies is important as it allows both a generic detection of the total amount of carbonylated proteins and an identification of the proteins selectively carbonylated.

CONTACT Alessandra Modesti alessandra.modesti@unifi.it @ Department of Biomedical, Experimental and Clinical Sciences "Mario Serio", University of Florence, Florence, Italy; Francesca Magherini francesca.magherini@unifi.it $@$ Department of Biomedical, Experimental and Clinical Sciences "Mario Serio", University of Florence, Viale Morgagni 50, Florence, Italy

(C) 2018 Informa UK Limited, trading as Taylor \& Francis Group 
A large-scale study of proteins is essential to investigate how carbonylation affects the protein function and to deepen whether there are common or preferential targets in the different processes where carbonylation occurs.

This review will briefly summarize the main methods to evaluate protein carbonylation and then will deal with the protein carbonylation changes induced by exercise mainly in plasma and skeletal muscle. Furthermore, particular attention will be devoted to those publications in which protein targets of carbonylation have been identified by proteomic approaches. We searched in Medline/PubMed and Embase with the subject heading protein carbonylation and keywords: exercise, physical activity, plasma protein carbonylation (PPC) and muscle protein carbonylation (MPC). We selected studies investigating the association of the effects of exercise on plasma and muscle irreversible oxidation. The search included articles published through January 1970 and March 2018. In this review, 26 articles accessible and available in English regarding the effect of physical exercise on plasma carbonyls formation and eight articles on the effect of exercise on skeletal muscles protein carbonylation were included. Furthermore, by searching the keywords proteomics, identification, PPC, MPC, we included four more papers.

As reported by Fedorova et al. 2014 [7], three methods are currently used to detect protein carbonyls. The main stages of these procedures can be summarized in: (i) biochemical and immunological techniques, were the measurement of protein plasma or muscle carbonyls was performed using immunoblot and/or ELISA Kits [8-13] (ii) spectrophotometric analyses [14-35] and (iii) proteomic approaches [36-41].

\section{Physical exercise and ROS/RNS production}

A proper practice of regular physical exercise has many health benefits including cardiovascular protection, reduction of the risk of obesity and diabetes, reinforcement of joints, hormonal control and delay of the aging process [42]. In skeletal muscles, ROS and RNS are usually synthesized at low levels and are required for normal force production [43-45]. Like ROS, RNS can be either harmful or beneficial to living systems since at high concentration inactivate important cellular molecules. The concentrations to which the shift from their advantageous to detrimental effects happens is not known. During exercise, ROS and RNS production increases and they are generated in different compartments within cells. Even if low levels of radicals are necessary for cell adaptation, intense physical activity and the consequent increase of oxygen consumption rate, can lead to an imbalance between production and disposal of ROS and this can induce the establishment of oxidative stress. This excess of free radicals can oxidize lipids, proteins and DNA, but proteins are the most vulnerable since radicals are able to create covalent bonds with amino acids residues leading to stable carbonyl moieties [7]. Common metabolic changes and inflammatory processes induced by muscle damage during physical exercise may play a role in ROS production. Mitochondria are considered the main source of intracellular ROS in muscle fibres. However, recent evidence suggests that only about $0.15 \%$ of mitochondrial oxygen utilized is converted into superoxide $\left(\mathrm{O}_{2}^{-} \cdot{ }^{-}\right)$[46]. In fact, $\mathrm{NAD}(\mathrm{P}) \mathrm{H}$ oxidase enzymes associated with the sarcoplasmic reticulum also release $\mathrm{O}_{2}{ }^{-}$. into the intracellular space. Furthermore, other plasma membrane redox systems are capable of transferring electrons from intracellular reductants to extracellular electron acceptors. The main oxidant under the RNS category is nitric oxide produced by NOSs (Nitric Oxide Synthases). Skeletal muscle normally expresses neuronal NOS and endothelial NOS. Neuronal NOS is primary expressed in fast-twitch muscle fibres. In contrast, endothelial NOS are localized in muscle mitochondria [47]. NO targets basically sulfhydryl groups in proteins by S-nitrosylation. In addition it reacts with superoxide anion to form peroxynitrite (ONOO-) and nitrogen dioxide $\left(\mathrm{NO}_{2}\right)$ able to target contractile proteins, key metabolic enzymes and sarcoplasmic reticulum. Moreover, peroxynitrite exerts direct oxidative effects on several molecules within the muscle fibres [48].

\section{Mitochondrial ROS/RNS production}

Mitochondria are the major source of ROS in cells. To carry out the oxidative phosphorylation (OXPHOS), the electrons arriving from glycolysis and TCA (tricarboxylic acid) cycle are transported across the enzymatic complexes of the electron transport chain (ETC) embedded in the inner mitochondrial membrane. This process leads to the final reduction of molecular oxygen $\left(\mathrm{O}_{2}\right)$ into water $\left(\mathrm{H}_{2} \mathrm{O}\right)$ and ATP production. During exhaustive exercise, a higher amount of ATP is required in muscle cells, so that mitochondrial aerobic respiration greatly increases. The higher rate of $\mathrm{O}_{2}$ consumption can lead to electrons leakage from the ETC and to incomplete $\mathrm{O}_{2}$ reduction, which causes the increase of superoxide $\left(\mathrm{O}_{2}^{-}\right)$, hydrogen peroxide $\left(\mathrm{H}_{2} \mathrm{O}_{2}\right)$ and hydroxyl radical $(\mathrm{OH})$. Complex I and Complex III are the main sites of $\mathrm{O}_{2}{ }^{-}$. production [49,50]. Furthermore, it has been demonstrated that mitochondria produce less ROS during state 3 of respiration (saturating 
ADP-stimulated respiration) than in state 4 (oligomycininduced respiration). This because in the presence of saturating $A D P$, mitochondrial respiration is more stimulated to reduce $\mathrm{O}_{2}$ into $\mathrm{H}_{2} \mathrm{O}$. In such condition, the mitochondrial transmembrane potential decreases to induce the rotational catalysis of the mitochondrial ATP synthase and produce ATP. It has been demonstrated a relation between the mitochondrial membrane potential and the entity of ROS production, both in intact cells and in isolated mitochondria [51]. Recently Sgarbi et al. reported that human fibroblasts forced to rely on OXPHOS to produce ATP, significantly decrease the amount of ROS in comparison with fibroblasts grown in normal metabolic conditions [52].

This point is very interesting since during contraction muscle cells need higher amount of ATP and, accordingly, mitochondria would decrease ROS production increasing OXPHOS.

\section{Non-mitochondrial ROS/RNS production}

Although this topic is still under debate, during physical exercise other cellular compartments clearly contribute to ROS/RNS generation. These sources include xanthine oxidase, NADPH oxidases and phospholipase A2dependent processes [53]. It has been seen that upon contraction, xanthine oxidase is able to induce lipid peroxidation and protein oxidation, leading to muscle injury [54]; NADPH oxidases seem to be involved in cytosolic superoxide production in skeletal muscle both at rest and during contraction; finally, phospholipase A2 triggers arachidonic acid cleavage and signalling leading to overproduction of ROS during physical exercise [55].

\section{Adaptation to oxidative stress during physical exercise}

ROS production is necessary for the adaptation to oxidative stress and this could explain why regular physical exercise decreases the incidence of oxidative stress-associated diseases [56-58]. The adaptation response presents several different aspects that overall explain the beneficial effects of physical activity on health. When skeletal muscle is subjected to exercise, it responds to the increased oxidative environment by increasing the antioxidant defence. Many research groups investigated the role of intermittent exercise/ interval training (which means stop and start at intervals) in ROS production. Intermittent exercise is both a description of the intensity of the activity as well as its nature and it is generally conducted at high intensity activity. Both acute and regular physical exercises are able to induce the increase of antioxidant enzymes if followed by a period of recovery. In fact, during recovery, muscles up-regulate the antioxidant defence and activate the repair systems against the oxidative damage [59-62]. Downstream effectors of ROS are several transcription factors such as NFkB (nuclear factor kappa-light-chain-enhancer of activated B cells), AP-1 (Activator Protein-1) and PGC1- $\alpha$ (peroxisome proliferator-activated receptor- $\gamma$ coactivator) $[63,64]$. Both NFkB and AP-1 are involved in the up-regulation of the antioxidant response as discussed by Brooks et al. [65], whereas PGC1- $\alpha$ is involved in mitochondrial biogenesis, which is one of the most important mechanisms induced by training. The activation of PGC1- $\alpha$ occurs via AMP kinase-dependent and independent pathways and according to the intensity of physical exercise $[66,67]$. An increased number of mitochondria is meant to satisfy the enhanced request of energy during intense exercise. In addition, PGC- $1 \alpha$ induces the removal of toxic components, by up-regulating antioxidant mechanisms, such as $[\mathrm{Cu}-\mathrm{Zn}]$ superoxide dismutase (SOD1), glutathione peroxidase (GPX) and Catalase (CAT), and also by increasing the expression of uncoupling protein 1 and 2 (UCP1 and UCP2), which dissipate the mitochondrial membrane potential and ROS content [68].

Furthermore, exercise can modify $\mathrm{NAD}^{+} / \mathrm{NADH}$ level thus modifying Sirtuin 1 (SIRT1) activity [8]. It has been shown that exercise increases SIRT1 expression level [69]: the reduction of cellular ATP/AMP ratio induced by exercise activates $A M P K$, leading to increased $N A D^{+}$ concentration. Such increase positively modulates SIRT1 deacetylating activity. The deacetylation of lysine residues on transcriptional regulators allows the metabolic adaptation of skeletal muscle to exercise performance. In fact, SIRT1 activation leads to the up-regulation of PGC$1 \alpha$, promoting the enhancement of OXPHOS. In addition, SIRT1 activation induces the degradation of old and damaged proteins via ubiquitin-proteasome system, thus preventing the accumulation of toxic components [70].

\section{Plasma protein carbonylation and exercise}

The terminology used for monitoring physical activity and exercise varies considerably. For this reason, the variation in terminology also makes difficult to track changes across studies. A classification of the type of physical exercise according to its intensity and to the extent of muscle effort is reported in Table 1, adapted from Norton et al., 2010 [71]. The effect of different types of exercise on PPC has been deeply investigated in humans $[9,36,72]$. Most of studies aim to clarify the relation between exercise and the redox state of plasma as protein carbonylation, presence of free thiols, 
antioxidant enzymes, TBARS (thiobarbituric acid reactive substances, formed as by-product of lipid peroxidation), TAC (total antioxidant capacity) and isoprostanes. Concerning carbonylation, most of studies report the evaluation of total carbonyl groups without identifying the specific targets of oxidation. Despite that, in these

Table 1. Classification of intensities of physical exercise and the corresponding measures.

\begin{tabular}{lc}
\hline Intensity of exercise & Measures of intensity \\
\hline Sedentary & $<1.6 \mathrm{METs}^{\mathrm{a}}$ \\
& $<20 \% \mathrm{VO}_{2 \max }$ \\
Light & $\mathrm{RPE}:<8$ \\
& $1.6-3 \mathrm{MET}$ \\
Moderate & $20-40 \% \mathrm{VO}_{2 \max }$ \\
& $\mathrm{RPE}: 8-10$ \\
Vigorous & $3-6 \mathrm{METs}$ \\
& $40-60 \% \mathrm{VO}_{2 \max }$ \\
High & $\mathrm{RPE}: 11-13$ \\
& $6-9 \mathrm{METs}$ \\
& $60-85 \% \mathrm{VO}_{2 \max }$ \\
& $\mathrm{RPE}: 14-16$ \\
& $\geq 9 \mathrm{METs}$ \\
RPE & $\geq 85 \% \mathrm{VO}_{2 \max }$ \\
$\mathrm{RPE} \geq 17$
\end{tabular}

$\mathrm{RPE}=$ rating of perceived exertion, according to Borg's scale. Figure adapted from Norton et al. (2010).

${ }^{\mathrm{a}} \mathrm{MET}$ (Metabolic Equivalent) $=3.5 \mathrm{ml}$ of consumed $\mathrm{O}_{2} / \mathrm{kg} / \mathrm{min}$. studies carbonylation seems to be affected by several factors such as the type of exercise performed, level of training, the time of sample collection and the antioxidant treatments. In order to reduce the complexity of the data, we do not include papers that analysed the effect of antioxidant supplementations along with exercise.

Exercise on cycle ergometer, treadmill and swimming are the commonly used methods to test plasma oxidative stress; furthermore, the effects of both aerobic and anaerobic exercises were investigated. These studies group participants in three different classes: athletes, nonprofessionally trained, and untrained individuals. Table 2 summarizes the major protein carbonylation changes in plasma of individuals after physical exercise at different intensities reported by different authors. Several papers evaluated PPC level in trained participants in comparison with sedentary individuals without focusing on one specific activity or type of exercise $[10,11,73]$. These researches demonstrated that in aerobic-trained participants the PPC is lower than in sedentary people. These data are in agreement with the well-proved concept that regular physical exercise induces an up-regulation of the antioxidant response.

Table 2. Protein carbonylation changes in plasma exposed to physical exercise reported by different authors.

\begin{tabular}{|c|c|c|c|}
\hline \multicolumn{4}{|c|}{ Human } \\
\hline \multicolumn{4}{|c|}{ Amateurs } \\
\hline Intensity of physical activity & Baseline training & PPC changes & References \\
\hline$\overline{\mathrm{HIGH}}$ & Yes & $\begin{array}{l}- \\
+ \\
=\end{array}$ & $\begin{array}{l}\text { Lo Presti et al., 2015; } \\
\text { Şentürk et al., 2005; Mullins et al., } 2013 \\
\text { Falone et al., 2010; Lo Presti et al., } 2015\end{array}$ \\
\hline $\mathrm{HIGH}$ & No & $\begin{array}{l}- \\
+ \\
=\end{array}$ & $\begin{array}{l}\text { Alessio et al., 2000; Şentürk et al., 2005; Berzosa et al., } \\
\text { 2011; Michailidis et al., } 2007 \\
\text { Falone et al., } 2012\end{array}$ \\
\hline VIGOROUS & Yes & $\begin{array}{l}- \\
+ \\
=\end{array}$ & $\begin{array}{l}\text { Lamprecht et al., 2008; Bloomer et al., 2007; Nikolaidis } \\
\text { et al., 2012; Boomer et al., } 2005 \\
\text { Lamprecht et al.,2008; }\end{array}$ \\
\hline VIGOROUS & No & $\begin{array}{l}- \\
+ \\
=\end{array}$ & $\begin{array}{l}\text { Michailidis et al., 2007; Silva et al., } 2010 \text { (supplementa- } \\
\text { tion); Lee et al., } 2002\end{array}$ \\
\hline $\begin{array}{l}\text { MODERATE } \\
\text { LIGHT } \\
\text { Not specified }\end{array}$ & $\begin{array}{l}\text { Yes } \\
\text { No } \\
\text { Yes }\end{array}$ & $\begin{array}{l}- \\
- \\
-\end{array}$ & $\begin{array}{l}\text { Zembron-Lacny et al., 2010; } \\
\text { Alessio et al., } 2000 \\
\text { Bloomer and Fisher-Wellman, } 2008\end{array}$ \\
\hline \multicolumn{4}{|c|}{ Athletes } \\
\hline Intensity of physical activity & $\begin{array}{l}\text { Participants' starting } \\
\text { level of training }\end{array}$ & PPC changes & References \\
\hline $\mathrm{HIGH}$ & Yes & $\begin{array}{l}- \\
+ \\
=\end{array}$ & $\begin{array}{l}\text { Radák et al., 2003; De Lucas et al., 2014; Stagos } \\
\text { et al., } 2015 \\
\text { Tanskanen et al., } 2010\end{array}$ \\
\hline VIGOROUS & Yes & $\begin{array}{l}- \\
+ \\
=\end{array}$ & Morillas-Ruiz et al., 2005 \\
\hline & & RATS & \\
\hline Intensity of physical activity & Baseline training & PPC changes & References \\
\hline $\begin{array}{l}\text { HIGH } \\
\text { LOW }\end{array}$ & $\begin{array}{c}\text { No or not specified } \\
\text { No }\end{array}$ & $\begin{array}{l}+ \\
=\end{array}$ & $\begin{array}{l}\text { Ramos et al., 2013; Veskoukis et al., } 2008 \\
\text { Ramos et al., } 2013\end{array}$ \\
\hline
\end{tabular}


Table 3. Mammalian fibre types and their main metabolic characteristics.

\begin{tabular}{lllll}
\hline & \multicolumn{4}{c}{ Fibre type } \\
\cline { 2 - 5 } & \multicolumn{1}{c}{ Type I } & \multicolumn{1}{c}{ Type Ila } & Type IIx/d & Type Ilb \\
\hline Metabolism & Oxidative & Oxidative/glycolytic & Glycolytic & Glycolytic \\
Mitochondrial efficiency & High & Intermediate & Low & Low \\
LDH & Low & Intermediate & High & High \\
Fatigue resistance & Slow twitch & Fast twitch & Fast twitch & Fast twitch \\
Shortening velocity & Resistant & Resistant & Fatigable & Fatigable \\
Force production & Weak & Intermediate & Strong & Strong \\
\hline
\end{tabular}

Adapted from Ferraro et al., 2014.

At the same time, an increased level of PPC has been observed after exhaustive aerobic exercise [14-19] with a single exception where no change was detected [73]. Furthermore, submaximal aerobic exercises lead to a significant increase in PPC level [12,20-22], and a correlation with the intensity and/or duration of exercise $[12,20]$ was observed. Other studies investigated the effect of anaerobic exercise using different protocols. Most of the authors detected an increase in PPC level after exercise [23-25]. On the contrary, Alessio et al. [14] did not detect change in PPC level assayed within $1 \mathrm{~h}$ from training. Bloomer et al. [26] observed that a single bout of squatting led to a slight increase of protein carbonylation immediately after the physical performance and a second significant peak of PPC was observed after 6 and $24 \mathrm{~h}$ from the exercise. In accordance Lee et al. [23] and Silva et al. [25] observed an increase in PPC levels $24 \mathrm{~h}$ - or even later - after eccentric exercise. These results clearly indicate that the time of sample collection and the procedure for sample preparation are important variables. In fact, after aerobic, nondamaging muscle training, the increase of PPC level can be detected immediately after the exercise and generally, it has a monophasic trend. On the contrary, in the case of anaerobic and especially muscledamaging exercise, PPC has a biphasic trend with one first peak detectable immediately after training, and a second one developing 24-48 h after the exercise [23]. The second peak is related to the muscle-damaging potential of high-force eccentric exercise. Phagocytes that produce RNS actively infiltrate damaged muscles, so that the increased oxidative stress is due to the activation of inflammatory processes rather than the production of free radicals from the mitochondrial ETC [74]. Furthermore, Wadley et al. [72] proposed that baseline protein carbonyls may be removed via proteasome 205 during exercise and, at the same time, exercise may induce the formation of new protein carbonyls. This would explain why some research groups did not detect significant changes in PPC immediately after exercise $[14,73]$.

Other studies investigated the possible modifications in the level of PPC in different sports (i.e. running, basketball, football). The content of protein carbonyls was found reduced in basketball players during the preparatory period and the play-off round suggesting that aerobic exercise enhances the antioxidant defence and reduces ROS generation in athletes [27]. This result is supported by the observation that trained athletes display lower levels of PPC at resting $[10,73]$ in comparison with nontrained subjects. On the other hand, exercises performed for a long period of time, such as a marathon, can induce oxidative damage even in well-trained athletes [28-30].

Another important factor to consider is the age of the participants. In fact, we recently demonstrated that functional fitness, a type of moderate training, significantly reduces PPC and enhances antioxidant efficiency in elderly [38].

The experiments performed in animal models confirmed the data obtained in humans [31]. In fact, Ramos et al. evaluated the oxidative stress biomarkers in plasma of untrained rats after a single bout of swimming exercise at low or high intensity and observed that PPC level resulted increased in the high intensity exercise group.

\section{Muscle protein carbonylation and exercise}

In this section, we will deepen the relationship existing between physical exercise and the oxidative changes occurring in skeletal muscles. In Table 3 are summarizes the main muscle fibre types and their metabolic characteristics in response to physical exercise (adapted from [75]). Notably, slow and fast-twitch fibres show different response to exercise [76]. In Table 4 are summarized and discussed below, the protein carbonylation in skeletal muscles from two animal models and humans after physical exercise at different intensities.

\section{Studies on animal models}

Most studies treating this topic have been carried out on animal models of rats and mice, since it is necessary to collect biopsies from skeletal muscle tissues. Several papers evidenced an increased level of MPC after 
Table 4. Protein carbonylation in skeletal muscles from two animal models and humans after physical exercise at different intensities.

\begin{tabular}{lcl}
\hline \multicolumn{3}{c}{ Rat/mice } \\
\hline Intensity of physical activity & PPC changes & \multicolumn{1}{c}{ References } \\
\hline HIGH & - & Koltai et al., 2010 \\
& + & Reznick et al., 1992 \\
& $=$ & Koltai et al., 2010; \\
MODERATE & + & Ramos et al., 2013 \\
LOW & + & You et al., 2005 \\
Human & Hyzewicz et al., 2015 \\
Intensity of physical activity & PPC changes & References \\
VIGOROUS-HIGH & + & Brocca et al., 2017 \\
MODERATE & + & Brocca et al., 2017 \\
\hline
\end{tabular}

exercise although, as reported for plasma, the data are not always in accordance. This because protein carbonylation is strongly affected by the time of sample collection and by the type of exercise administered.

First, we to summarize the results obtained in studies where animals were exposed to a physical activity of vigorous intensity $\left(60 \%-75 \% \mathrm{VO}_{2 \text { max }}\right)$. Koltai and coworkers [8] administered intense treadmill running to young and old rats forcing these to reach $60 \% \mathrm{VO}_{2 \max }$. No significant variations were detected in protein carbonylation levels from gastrocnemius muscle of young rats, whereas a decrease was observed in muscles collected from old rats. In addition, Radak et al. demonstrated that the total amount of carbonyls did not increase after 9 weeks of swimming in rats [32]. At the same time, the authors showed through western blot a significantly higher content of reactive carbonyl derivatives in proteins having molecular weight around $29 \mathrm{kDa}$ extracted from muscles of control animals with respect to the muscles obtained from trained animals.

The total amount of carbonyls was also investigated in skeletal muscles of rats subjected to long-term moderate exercise $\left(40 \%-60 \% \mathrm{VO}_{2 \max }\right)$ [33]. The study began in young rats and was continued throughout their adulthood and aging. In muscles obtained from trained rats, the total amount of carbonyls was found reduced, whereas an increase of carbonyls was detected in heart. In addition, Silva et al. [34] described a decrease in MPC level in in quadriceps muscles of young mice after an 8 weeks-training program of aerobic running; on the contrary they showed an increase in protein carbonylation after eccentric running.

Finally, Hyzewicz and co-workers [39] showed that a low-intensity exercise (about $30-40 \% \mathrm{VO}_{2 \max }$ ) in wild type mice increased MPC in gastrocnemius after $1 \mathrm{~h}$. Such oxidation remained elevated even 2 days after training.
With regard to single bouts of exercise, Reznick et al. [35] provided the first evidence that, in rats, a single bout of exhaustive running or endurance training induced MPC in gastrocnemius, rectus femoris and quadricep femoris. The effect of a single bout of exercise (at low and high intensity) on total amount of carbonyls was also evaluated by Ramos et al. in untrained rats [31]. These authors did not detect any change in MPC, whilst an increased level of oxidized proteins was found in plasma after high intensity single bout.

\section{Studies on humans}

A very recent publication reports a study on MPC level of healthy and physically active young and older men [13]. The type of exercise was a continuative physical activity, either moderate or intense, performed at least three times per week and for at least 3 years, with the purpose to improve health and fitness. Biopsies of vastus lateralis muscles were taken to study protein carbonylation. Protein carbonyls were derivatized with DNPH and analysed through Western blot and anti-DNP immunodetection and MPC was found higher in elderly than in younger men, as consequence of the physiological oxidative stress occurring in aging.

\section{Cellular turnover of carbonylated proteins}

Several authors examined the effect of physical activity on protein carbonylation in plasma and skeletal muscles and observed different responses according to type, intensity and duration of exercise. However, when a panel of carbonylated proteins is detected, it is possible to obtain a picture of a dynamic equilibrium between production and degradation of carbonyls.

Moreover sampling time is a determining fact for measurement of oxidative stress induced by exercise. Several authors reported that there is a best time point for each markers of oxidative stress [16]. Regarding protein carbonyls, their concentration remains elevated for a prolonged period after exercise; this because increased production of reactive oxygen and nitrogen species after cessation of exercise contributed to the elevated levels of protein carbonyls. Removal of oxidized proteins from blood is a time-consuming process. Certainly, types of exercise or longer-duration exercise, may affect oxidative stress differently. Several studies suggest that the degree of oxidative stress may be attenuated by training. Finally, muscle damage plays major role in determining the effect of exercise on the time course of oxidative stress. All things considered, we 
believe important to deepen the turnover of carbonylated proteins.

Interestingly, the degradation processes and the proteins turnover are different among mitochondria, intracellular or extracellular fluids $[77,78]$.

\section{Cytosolic protein turnover}

It has been demonstrated that carbonylated proteins are more inclined to proteolytic digestion with respect to the nonoxidized counterparts [79] and the proteasome machinery is clearly involved in the degradation of protein carbonyls. The $20 \mathrm{~S}$ proteasome is composed of a 205 catalytic core where the degraded proteins are tagged with ubiquitin via an ATP-independent mechanism. The $26 \mathrm{~S}$ proteasome, which consists of the $20 \mathrm{~S}$ core unit and two 19S regulatory unit, is able to degrade proteins using ATP [80]. Much evidence indicates that the majority of oxidized proteins are not ubiquitinated, but are eliminated by the $20 \mathrm{~S}$ system [81-83]. It is also necessary to underline that highly oxidized proteins tend to form aggregates that are not substrate for the proteasome, but instead inhibit the proteasome activity. Therefore, the level of protein aggregates is significantly higher when proteins are carbonylated and this requires a fast clearance of carbonyls to maintain cell homeostasis [7]. Another intriguing hypothesis is the involvement of autophagy in the elimination of carbonylated proteins or aggregates. Autophagy is a fundamental mechanism for the maintenance of cell homeostasis: it is involved in the removal of old and damaged organelles, as well as in the degradation of oxidized molecules $[84,85]$. In addition, it has been observed that autophagy is fundamental for the maintenance of healthy skeletal muscles. In fact, dysregulated autophagy has been associated with several conditions, such as dystrophies and sarcopenia, where the oxidative damage is considered a major player [86-88].

\section{Mitochondrial proteins turnover}

In mitochondria, several types of metabolic pathways are present to monitor and remove oxidized proteins [89]. According to Voos et al. [90] in yeast, several chaperones are involved in keeping damaged proteins in soluble, non-aggregated state allowing their proteolysis. In mammalian mitochondria, two main families of proteases are known to be involved in this mechanism: the ATP-dependent serine proteases, Lon, TOR1A/B and paraplegin, and the ATP-independent mitochondrial processing peptidase (MPP). Dysfunctions occurring in these enzymes have been associated with human diseases or conditions. For instance, down-regulation of Lon is observed during aging; mutations of paraplegin and TOR1A/B occur in hereditary spastic paraplegia and idiopathic torsion dystonia; modifications of MPP are seen in Friedrich ataxia [91].

Furthermore, mitochondria can control the amount of damaged proteins through the fusion process with healthy mitochondria, thus diluting the content of oxidized proteins. Lastly, mitochondrial autophagy, or mitophagy, represents another important mechanism to eliminate irreversibly damaged mitochondria and oxidized mitochondrial proteins [92].

\section{Plasma proteins turnover}

In plasma, free thiol groups, largely located on albumin, are the most important scavengers of oxidants [93]. Instead, in contrast to what is observed in the cellular environment, plasma is characterized by very low concentrations of superoxide dismutases, glutathione and catalase. However, the knowledge on the processes involved in the removal of plasma-oxidized proteins is still very poor.

\section{Protein decarbonylation}

As previously reported by many authors, protein oxidation plays a key role in both oxidative stress and redox signalling. Protein carbonylation increases in response to aging and diseases, labelling damaged proteins in order to be eliminated from the biological systems. However, a recent hypothesis by Wong et al. (2012) suggests that the formation of protein carbonyls may be a reversible reaction [94]. The authors observed that by inducing protein carbonylation through endothelin1 treatment on smooth muscle cells, the level of protein carbonyls increases in the first $10 \mathrm{~min}$ and then it tends to return at the basal level. The authors proposed that this phenomenon may not be linked to an increased protein proteasome-dependent degradation, but rather to the activation of protein decarbonylation, by demonstrating that the inhibition of the proteasome did not suppress the decarbonylation process. One mechanism suggested involves the activation of the antioxidant enzyme thioredoxin [95]. The authors proposed that this enzyme could act as a biological thiol able to donate electrons to reduce the carbonylated proteins. Moreover, Hyzewicz et al. [39] investigated for the first time the effect of low intensity training at protein level on exercised $m d x$ muscle of mice. They reported a decrease in protein carbonylation and an increase of 
Table 5. Proteins target of carbonylation following aerobic physical exercise.

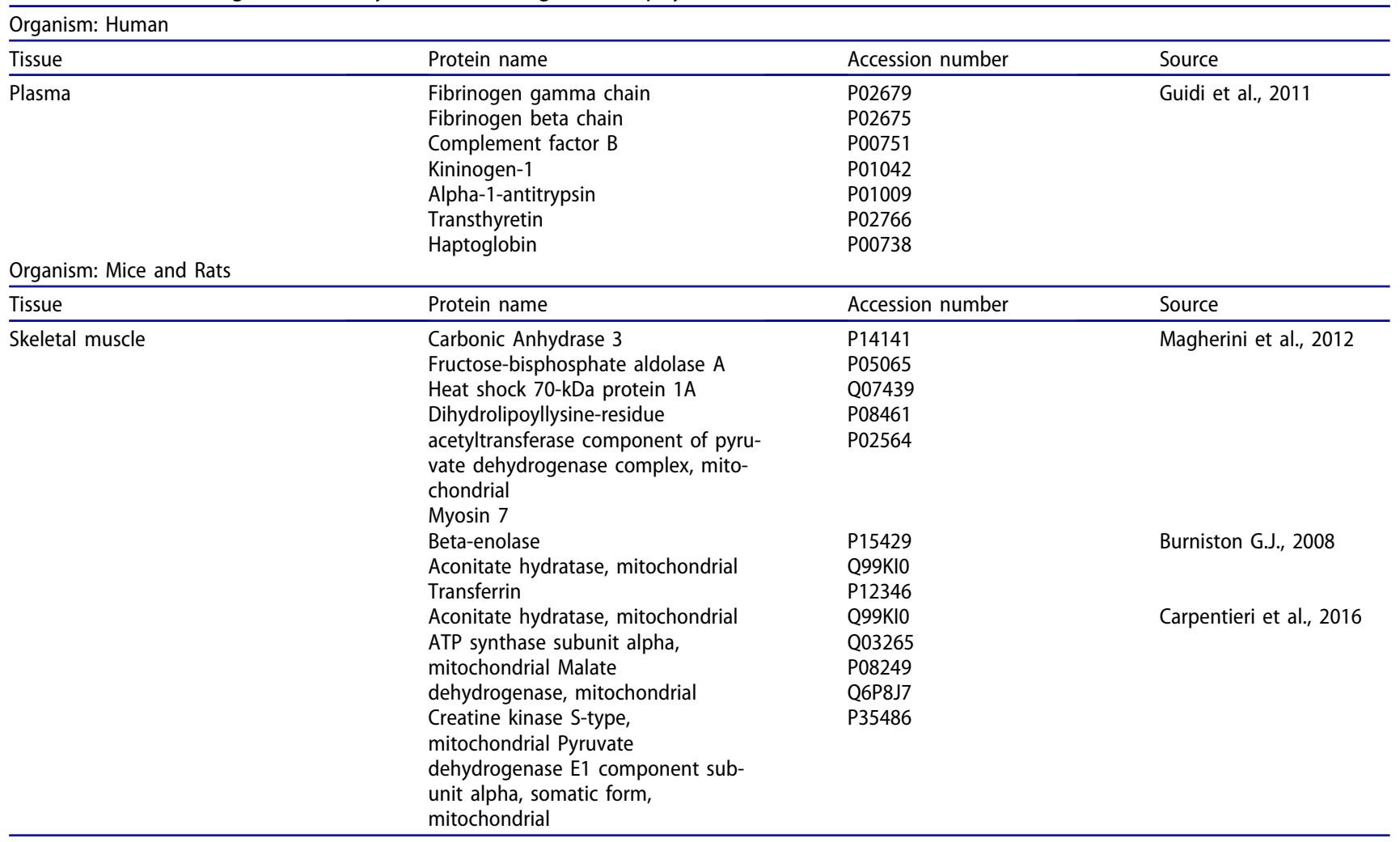

the expression levels of several proteins involved in muscle contraction.

Suzuki et al. [96] proposed two functions of protein decarbonylation in oxidative stress and redox signaling: (i) the first one involving peroxiredoxins phosphorylation and hyperoxidation and (ii) the second one promoting site-directed mutagenesis-like reactions induced by ROS action that convert specific amino acids into others (i.e. arginine and proline residues to glutamic acid), thus generating a protein with altered structure. The hypothesis on the existence of protein decarbonylation processes opens new perspectives on the dynamics of protein carbonyls formation and their possible degradation as a novel mechanism in cellular signalling.

\section{Contribution of proteomics}

\section{PPC}

Recently our group performed a proteomic study on PPC in humans before and after two controlled training protocols (resistance exercise and power exercise) [36]. We did not detect any differences between the groups regarding the total carbonyls amount. Two-dimensional electrophoresis followed by western blot and immunodetection against carbonylated proteins demonstrated that there is a great variability between subjects in resting condition, indicating that basal carbonylation levels are severely influenced by different factors (lifestyle, genetic background) that have not been still deeply investigated in detail [36]. When we analysed the protein carbonylation variation before and after exercise in the same athletes, we identified 12 different proteins, as common target of carbonylation, regardless of the physical activity conducted. Among these, haptoglobin, transthyretin and complement factor B showed an increased carbonylation level after both types of exercise. Instead, serotransferrin and vitamin $D$ binding protein showed a decreased carbonylation level following both types of exercise.

The variability among subjects also emerged in the study of Mullins et al. [19]. Unfortunately, no other studies are present in literature reporting plasma protein carbonyls identification in relation to exercise.

\section{MPC}

With regard to the identification of $M P C$, few studies were performed and the few present are carried out using animal models. Our group analysed, by twodimensional electrophoresis and western blot, the proteins selectively carbonylated in limb muscles of rats subjected to aerobic training at vigorous intensity $(80 \%$ 
$\left.V O_{2 \max }\right)$. In this study, we found an increased level of carbonylation for several proteins (see Table 5) [40].

We recently [37] identified mitochondrial proteins as the main targets of carbonylation in heart and tibialis anterior from mice exposed to endurance physical activity. Mass spectrometry analysis indicated methionine, cysteine, proline and leucine residues as main targets. The main proteins involved from tibialis anterior were ATP synthase- $\alpha$ subunit, creatine kinase S-type, aconitate hydratase, pyruvate dehydrogenase E1 component subunit $\alpha$ and malate dehydrogenase. Some of these proteins were also found as targets of carbonylation in the study performed by Burniston [41]. It is also interesting to note that in mitochondria isolated from heart we observed a decreased carbonylation level in several proteins after exercise. A possible explanation of this finding can be due to the different antioxidant environment. In fact, the mitochondrial antioxidant systems differ between heart and skeletal muscle [97-99]. This may be related to the different metabolism occurring in heart and tibialis anterior; in heart, the oxidative metabolism needs a more protective environment against ROS, on the contrary, a fermentative muscle does not. In fact, in heart, the request of ATP is satisfied by the free fatty acids catabolism-driven OXPHOS; on the contrary in tibialis anterior, which is a predominantly fast-contracting muscle, ATP is mainly produced from glucose-dependent fermantation. It was further observed [99] that a single bout of swimming caused a reduction of carbonylation in several proteins of tibialis anterior and extensor digitorum longus. Finally, Fedorova et al. [100] aimed to identify the main protein targets of MPC on a rat model of acute oxidative stress even if no due to physical exercise. The proteins found carbonylated were all involved in muscle tissue contraction: actin, myosin, tropomyosin and troponin. Overall, several muscular proteins resulted carbonylated at basal level, as reported for plasma. Therefore, the important questions are: (1) How much can this basal level be modified without causing deleterious effects for muscles? (2) Are there specific proteins whose function can be affected by carbonylation? The identification by proteomic approaches of specific protein targets of carbonylation could greatly contribute to answer these questions and could be useful to verify a cause-effect relationship between the oxidation of specific proteins and the impairment of specific cellular functions. The second important point is that variations in MPC depend on the type of exercise and on the type of muscle. In the light of all this, the information coming from these studies is insufficient to drive a unique conclusion.

\section{Conclusions}

In this review, we reported a large analysis of the current knowledge on the effect of physical exercise on protein carbonylation in plasma and skeletal muscle and we can conclude that, from the comprehensive bibliography analysed, there is no clearly defined specific physiological role about this post-translational modification of proteins during physical exercise.

In both plasma and skeletal muscles, the physiological levels of protein carbonylation can be either increased, decreased or not being changed, depending on the type and the intensity of physical exercise and most of the authors highlighted the presence of basal levels of protein carbonylation under physiological conditions.

This may suggest that basal levels of protein carbonylation is independent by physical exercise and exogenous oxidative stress, and the presence of these carbonylated proteins is well-tolerated in mammalian cells. In addition, basal carbonylation levels of contractile proteins may contribute to a partial and reversible down-regulation of the contractile apparatus during steady-state conditions; the same may be true for some metabolic enzymes involved in energy usage. Further studies are necessary in order to evaluate if in sport-related diseases the amount of muscle mass loss and its function can be attributed to protein carbonylation. Proteomics techniques will help to to the identify of the residues that are particularly carbonylated according to the different types and intensity of physical activity practiced by athletes and it will be the subject of future research. Moreover, although protein carbonylation has always been described as an irreversible mechanism leading to a definitive modification of protein function [2], a recent hypothesis suggests that the formation of protein carbonyls may be a reversible reaction [94]. So far, only one mechanism has been suggested in this scenario and involves the activation of the antioxidant enzyme thioredoxin [95]. This new point of view opens new perspectives on the dynamics of protein carbonyls formation, and throws an important - and at the same time intriguing - question: is protein carbonylation irreversible?

\section{Disclosure statement}

No potential conflict of interest was reported by the authors.

\section{References}

[1] Levine RL. Carbonyl modified proteins in cellular regulation, aging, and disease. Free Radic Biol Med. 2002;32(9):790-796. 
[2] Dalle-Donne I, Giustarini D, Colombo R, et al. Protein carbonylation in human diseases. Trends Mol Med. 2003;9(4):169-176.

[3] Tramutola A, Lanzillotta C, Perluigi M, et al. Oxidative stress, protein modification and Alzheimer disease. Brain Res Bull. 2017;133:88-96.

[4] Requena JR, Levine RL, Stadtman ER. Recent advances in the analysis of oxidized proteins. Amino Acids. 2003;25(3-4):221-226.

[5] Suzuki YJ, Carini M, Butterfield DA. Protein carbonylation. Antioxid Redox Signal. 2010;12(3):323-325.

[6] Wong CM, Marcocci L, Liu L, et al. Cell signaling by protein carbonylation and decarbonylation. Antioxid Redox Signal. 2010;12(3):393-404.

[7] Fedorova M, Bollineni RC, Hoffmann R. Protein carbonylation as a major hallmark of oxidative damage: update of analytical strategies. Mass Spectrom Rev. 2014;33(2):79-97.

[8] Koltai E, Szabo Z, Atalay $M$, et al. Exercise alters SIRT1, SIRT6, NAD and NAMPT levels in skeletal muscle of aged rats. Mech Ageing Dev. 2010;131(1): 21-28.

[9] Afzalpour ME, et al. Plasma protein carbonyl responses to anaerobic exercise in female cyclists. Int J Appl Exer Physiol. 2016;5(1):53-58.

[10] Lo Presti R, Canino B, Cilluffo $P$, et al. Protein carbonyl groups in trained subjects before and after a cardiopulmonary test. Clin Hemorheol Microcirc. 2015;59(1):27-35.

[11] Bloomer RJ, Fisher-Wellman KH. Blood oxidative stress biomarkers: influence of sex, exercise training status, and dietary intake. Gend Med. 2008;5(3): 218-228.

[12] Lamprecht $M$, Greilberger JF, Schwaberger G, et al. Single bouts of exercise affect albumin redox state and carbonyl groups on plasma protein of trained men in a workload-dependent manner. J Appl Physiol. (1985) 2008;104(6):1611-1617 [doi:10.1152/ japplphysiol.01325.2007] [PubMed: 18420715].

[13] Brocca L, McPhee JS, Longa E, et al. Structure and function of human muscle fibres and muscle proteome in physically active older men. J Physiol. 2017; 595(14):4823-4844.

[14] Alessio $H M$, Hagerman $A E$, Fulkerson $B K$, et al. Generation of reactive oxygen species after exhaustive aerobic and isometric exercise. Med Sci Sports Exerc. 2000;32(9):1576-1581.

[15] Berzosa C, Gómez-Trullén EM, Piedrafita E, et al. Erythrocyte membrane fluidity and indices of plasmatic oxidative damage after acute physical exercise in humans. Eur J Appl Physiol. 2011;111(6):1127-1133.

[16] Michailidis $Y$, Jamurtas AZ, Nikolaidis $M G$, et al. Sampling time is crucial for measurement of aerobic exercise-induced oxidative stress. Med Sci Sports Exerc. 2007;39(7):1107-1113.

[17] Sentürk UK, Gündüz $F$, Kuru $O$, et al. Exerciseinduced oxidative stress leads hemolysis in sedentary but not trained humans. J Appl Physiol. (1985) 2005; 99(4):1434-1441.

[18] Tanskanen M, Atalay M, Uusitalo A. Altered oxidative stress in overtrained athletes. J Sports Sci. 2010;28(3): 309-317.
[19] Mullins AL, van Rosendal SP, Briskey DR, et al. Variability in oxidative stress biomarkers following a maximal exercise test. Biomarkers. 2013;18(5):446-454.

[20] Bloomer RJ, Davis PG, Consitt LA, et al. Plasma protein carbonyl response to increasing exercise duration in aerobically trained men and women. Int $J$ Sports Med. 2007;28(1):21-25.

[21] Morillas-Ruiz J, Zafrilla $P$, Almar $M$, et al. The effects of an antioxidant-supplemented beverage on exercise-induced oxidative stress: results from a placebocontrolled double-blind study in cyclists. Eur J Appl Physiol. 2005;95(5-6):543-549.

[22] Nikolaidis MG, Kyparos A, Dipla K, et al. Exercise as a model to study redox homeostasis in blood: the effect of protocol and sampling point. Biomarkers. 2012;17(1):28-35.

[23] Lee J, Goldfarb $\mathrm{AH}$, Rescino $\mathrm{MH}$, et al. Eccentric exercise effect on blood oxidative-stress markers and delayed onset of muscle soreness. Med Sci Sports Exerc. 2002;34(3):443-448.

[24] Silva LA, Silveira PCL, Pinho CA, et al. N-acetylcysteine supplementation and oxidative damage and inflammatory response after eccentric exercise. Int $J$ Sport Nutr Exerc Metab. 2008;18(4):379-388.

[25] Silva LA, Pinho CA, Silveira PC, et al. Vitamin E supplementation decreases muscular and oxidative damage but not inflammatory response induced by eccentric contraction. J Physiol Sci. 2010;60(1):51-57.

[26] Bloomer RJ, Goldfarb AH, Wideman L, et al. Effects of acute aerobic and anaerobic exercise on blood markers of oxidative stress. J Strength Cond Res. 2005;19(2):276-285.

[27] Zembron-Lacny A, Slowinska-Lisowska M, Ziemba A. Integration of the thiol redox status with cytokine response to physical training in professional basketball players. Physiol Res. 2010;59(2):239-245.

[28] Radák Z, Ogonovszky H, Dubecz J, et al. Super-marathon race increases serum and urinary nitrotyrosine and carbonyl levels. Eur J Clin Invest. 2003;33(8): 726-730.

[29] de Lucas RD, Caputo F, Mendes de Souza K, et al. Increased platelet oxidative metabolism, blood oxidative stress and neopterin levels after ultra-endurance exercise. J Sports Sci 2014;32(1):22-30.

[30] Stagos D, Goutzourelas N, Bar-Or D, et al. Application of a new oxidation-reduction potential assessment method in strenuous exercise-induced oxidative stress. Redox Rep. 2015;20(4):154-162.

[31] Ramos D, Martins EG, Viana-Gomes D, et al. Biomarkers of oxidative stress and tissue damage released by muscle and liver after a single bout of swimming exercise. Appl Physiol Nutr Metab. 2013; 38(5):507-511.

[32] Radák Z, Kaneko T, Tahara S, et al. The effect of exercise training on oxidative damage of lipids, proteins, and DNA in rat skeletal muscle: evidence for beneficial outcomes. Free Radic Biol Med. 1999;27(1-2): 69-74.

[33] Bayod S, Del Valle J, Lalanza JF, et al. Long-term physical exercise induces changes in sirtuin 1 pathway and oxidative parameters in adult rat tissues. Exp Gerontol. 2012;47(12):925-935. 
[34] Silva LA, Bom KF, Tromm CB, et al. Effect of eccentric training on mitochondrial function and oxidative stress in the skeletal muscle of rats. Braz J Med Biol Res. 2013;46(1):14-20.

[35] Reznick AZ, Witt E, Matsumoto $M$, et al. Vitamin $E$ inhibits protein oxidation in skeletal muscle of resting and exercised rats. Biochem Biophys Res Commun. 1992;189(2):801-806.

[36] Guidi F, Magherini F, Gamberi T, et al. Plasma protein carbonylation and physical exercise. Mol Biosyst. 2011;7(3):640-650.

[37] Carpentieri A, Gamberi T, Modesti A, et al. Profiling carbonylated proteins in heart and skeletal muscle mitochondria from trained and untrained mice. J Proteome Res. 2016;15(10):3666-3678.

[38] Gamberi $T$, et al. Effect of functional fitness on plasma oxidation level in elders: reduction of the plasma oxidants and improvement of the antioxidant barrier. Am J Sports Sci. 2018;6(2):55-64.

[39] Hyzewicz J, Tanihata J, Kuraoka M, et al. Low intensity training of $\mathrm{mdx}$ mice reduces carbonylation and increases expression levels of proteins involved in energy metabolism and muscle contraction. Free Radic Biol Med. 2015;82:122-136.

[40] Magherini F, Abruzzo PM, Puglia M, et al. Proteomic analysis and protein carbonylation profile in trained and untrained rat muscles. J Proteom. 2012;75(3): 978-992.

[41] Burniston JG. Changes in the rat skeletal muscle proteome induced by moderate-intensity endurance exercise. Biochim Biophys Acta. 2008;1784(7-8):1077-1086.

[42] Jacomini AM, Dias DD, Brito JO, et al. Influence of estimated training status on anti and pro-oxidant activity, nitrite concentration, and blood pressure in middle-aged and older women. Front Physiol. 2017; 8:122.

[43] Radak Z, Zhao Z, Koltai E, et al. Oxygen consumption and usage during physical exercise: the balance between oxidative stress and ROS-dependent adaptive signaling. Antioxid Redox Signal. 2013;18(10):1208-1246.

[44] Alleman RJ, Katunga LA, Nelson MAM, et al. The "Goldilocks Zone" from a redox perspective - adaptive vs. deleterious responses to oxidative stress in striated muscle. Front Physiol. 2014;5:358.

[45] Role of ROS and RNS sources in physiological and pathological conditions; 2016. [Online]. Available from: https://www.hindawi.com/journals/omcl/2016/ 1245049/. Accessed: 29 Jul, 2018.

[46] St-Pierre J, Buckingham JA, Roebuck SJ, et al. Topology of superoxide production from different sites in the mitochondrial electron transport chain. J Biol Chem. 2002;277(47):44784-44790.

[47] Gondim FJ, Modolo LV, Campos GER, et al. Neuronal nitric oxide synthase is heterogeneously distributed in equine myofibers and highly expressed in endurance trained horses. Can J Vet Res. 2005;69(1):46-52.

[48] Barreiro E. Role of protein carbonylation in skeletal muscle mass loss associated with chronic conditions. Proteomes Rev. 2016;4(2).

[49] Brand MD. The sites and topology of mitochondrial superoxide production. Exp Gerontol. 2010;45(7-8): 466-472.
[50] Muller FL, Liu Y, Van Remmen HV. Complex III releases superoxide to both sides of the inner mitochondrial membrane. J Biol Chem. 2004;279(47): 49064-49073.

[51] Suski JM, Lebiedzinska $M$, Bonora $M$, et al. Relation between mitochondrial membrane potential and ROS formation. Methods Mol Biol. 2012;810:183-205.

[52] Sgarbi G, Gorini G, Costanzini A, et al. Hypoxia decreases ROS level in human fibroblasts. Int J Biochem Cell Biol. 2017;88:133-144.

[53] Powers SK, Jackson MJ. Exercise-induced oxidative stress: cellular mechanisms and impact on muscle force production. Physiol Rev. 2008;88(4):1243-1276.

[54] Judge AR, Dodd SL. Xanthine oxidase and activated neutrophils cause oxidative damage to skeletal muscle after contractile claudication. Am J Physiol Heart Circ Physiol. 2004;286(1):H252-H256.

[55] Steinbacher P, Eckl P. Impact of oxidative stress on exercising skeletal muscle. Biomolecules. 2015;5(2): 356-377.

[56] Roque FR, Briones AM, García-Redondo AB, et al. Aerobic exercise reduces oxidative stress and improves vascular changes of small mesenteric and coronary arteries in hypertension. $\mathrm{Br} \mathrm{J}$ Pharmacol. 2013;168(3):686-703.

[57] Oh S, Tanaka K, Warabi E, et al. Exercise reduces inflammation and oxidative stress in obesity-related liver diseases. Med Sci Sports Exerc. 2013;45(12): 2214-2222.

[58] Korsager Larsen M, Matchkov VV. Hypertension and physical exercise: the role of oxidative stress. Medicina. 2016;52(1):19-27.

[59] Ookawara T, Haga S, Ha S, et al. Effects of endurance training on three superoxide dismutase isoenzymes in human plasma. Free Radic Res. 2003;37(7): 713-719.

[60] Hitomi Y, Watanabe S, Kizaki T, et al. Acute exercise increases expression of extracellular superoxide dismutase in skeletal muscle and the aorta. Redox Rep. 2008;13(5):213-216.

[61] Gomez-Cabrera MC, Domenech E, Viña J. Moderate exercise is an antioxidant: upregulation of antioxidant genes by training. Free Radic Biol Med. 2008; 44(2):126-131.

[62] Fransson D, Nielsen TS, Olsson K, et al. Skeletal muscle and performance adaptations to high-intensity training in elite male soccer players: speed endurance runs versus small-sided game training. Eur J Appl Physiol. 2018;118(1):111-121.

[63] Ji LL. Modulation of skeletal muscle antioxidant defense by exercise: role of redox signaling. Free Radic Biol Med. 2008;44(2):142-152.

[64] Mason SA, Morrison D, McConell GK, et al. Muscle redox signalling pathways in exercise. Role of antioxidants. Free Radic Biol Med. 2016;98:29-45.

[65] Brooks SV, Vasilaki A, Larkin LM, et al. Repeated bouts of aerobic exercise lead to reductions in skeletal muscle free radical generation and nuclear factor kappaB activation. J Physiol. 2008;586(16): 3979-3990.

[66] Irrcher I, Ljubicic V, Hood DA. Interactions between ROS and AMP kinase activity in the regulation of 
PGC-1alpha transcription in skeletal muscle cells. Am J Physiol Cell Physiol. 2009;296(1):C116-C123.

[67] Brandt N, Dethlefsen MM, Bangsbo J, et al. PGC-1 $\alpha$ and exercise intensity dependent adaptations in mouse skeletal muscle. PLOS ONE. 2017;12(10): e0185993.

[68] Thirupathi A, de Souza CT. Multi-regulatory network of ROS: the interconnection of ROS, PGC-1 alpha, and AMPK-SIRT1 during exercise. J Physiol Biochem. 2017;73(4):487-494.

[69] Huang CC, Wang T, Tung YT, et al. Effect of exercise training on skeletal muscle SIRT1 and PGC- $1 \alpha$ expression levels in rats of different age. Int J Med Sci. 2016;13(4):260-270.

[70] Liao ZY, Chen JL, Xiao MH, et al. The effect of exercise, resveratrol or their combination on sarcopenia in aged rats via regulation of AMPK/Sirt1 pathway. Exp Gerontol. 2017;98:177-183.

[71] Norton K, Norton L, Sadgrove D. Position statement on physical activity and exercise intensity terminology. J Sci Med Sport. 2010;13(5):496-502 [doi: 10.1016/j.jsams.2009.09.008] [PubMed: 20005170].

[72] Wadley AJ, Turner JE, Aldred S. Factors influencing post-exercise plasma protein carbonyl concentration. Free Radic Res. 2016;50(4):375-384.

[73] Falone S, Mirabilio A, Pennelli A, et al. Differential impact of acute bout of exercise on redox- and oxidative damage-related profiles between untrained subjects and amateur runners. Physiol Res. 2010; 59(6):953-961.

[74] Niess AM, Simon P. Response and adaptation of skeletal muscle to exercise - the role of reactive oxygen species. Front Biosci. 2007;12:4826-4838.

[75] Ferraro E, Giammarioli AM, Chiandotto S, et al. Exercise-induced skeletal muscle remodeling and metabolic adaptation: redox signaling and role of autophagy. Antioxid Redox Signal. 2014;21(1): 154-176.

[76] Bogdanis GC. Effects of physical activity and inactivity on muscle fatigue. Front Physiol. 2012;3:142.

[77] Amm I, Sommer T, Wolf DH. Protein quality control and elimination of protein waste: the role of the ubiquitin-proteasome system. Biochim Biophys Acta. 2014;1843(1):182-196.

[78] Bohovych I, Chan SSL, Khalimonchuk O. Mitochondrial protein quality control: the mechanisms guarding mitochondrial health. Antioxid Redox Signal. 2015;22(12):977-994.

[79] Nyström T. Role of oxidative carbonylation in protein quality control and senescence. EMBO J. 2005;24(7): 1311-1317.

[80] Jung T, Catalgol B, Grune T. The proteasomal system. Mol Aspects Med. 2009;30(4):191-296.

[81] Kastle M, Grune T. Protein oxidative modification in the aging organism and the role of the ubiquitin proteasomal system. Curr Pharm Des. 2011;17(36):4007-4022.

[82] Kästle M, Grune T. Interactions of the proteasomal system with chaperones: protein triage and protein quality control. Prog Mol Biol Transl Sci. 2012;109: 113-160.
[83] Jung T, Höhn A, Grune T. The proteasome and the degradation of oxidized proteins: part II - protein oxidation and proteasomal degradation. Redox Biol 2014;2:99-104.

[84] Zhao $\mathrm{Y}$, Zhang $\mathrm{CF}$, Rossiter $\mathrm{H}$, et al. Autophagy is induced by UVA and promotes removal of oxidized phospholipids and protein aggregates in epidermal keratinocytes. J Invest Dermatol. 2013;133(6): 1629-1637.

[85] Filomeni G, De Zio D, Cecconi F. Oxidative stress and autophagy: the clash between damage and metabolic needs. Cell Death Differ. 2015;22(3):377-388.

[86] Jiao J, Demontis F. Skeletal muscle autophagy and its role in sarcopenia and organismal aging. Curr Opin Pharmacol. 2017;34:1-6.

[87] Can B, Kara O, Kizilarslanoglu MC, et al. Serum markers of inflammation and oxidative stress in sarcopenia. Aging Clin Exp Res. 2017;29(4):745-752.

[88] Murphy ME, Kehrer JP. Oxidative stress and muscular dystrophy. Chem Biol Interact. 1989;69(2-3):101-173.

[89] Smakowska E, Czarna M, Janska H. Mitochondrial ATP-dependent proteases in protection against accumulation of carbonylated proteins. Mitochondrion. 2014;19(B):245-251.

[90] Voos W. Chaperone-protease networks in mitochondrial protein homeostasis. Biochim Biophys Acta. 2013;1833(2):388-399.

[91] Bota DA, Davies KJA. Protein degradation in mitochondria: implications for oxidative stress, aging and disease: a novel etiological classification of mitochondrial proteolytic disorders. Mitochondrion. 2001; 1(1):33-49.

[92] Twig G, Shirihai OS. The interplay between mitochondrial dynamics and mitophagy. Antioxid Redox Signal. 2011;14(10):1939-1951.

[93] Himmelfarb J, McMonagle E. Albumin is the major plasma protein target of oxidant stress in uremia. Kidney Int. 2001;60(1):358-363.

[94] Wong CM, Bansal G, Marcocci L, et al. Proposed role of primary protein carbonylation in cell signaling. Redox Rep. 2012;17(2):90-94.

[95] Wong CM, Cheema AK, Zhang L, et al. Protein carbonylation as a novel mechanism in redox signaling. Circ Res. 2008;102(3):310-318.

[96] Suzuki YJ. Mechanism and functions of protein decarbonylation. In: Protein carbonylation. WileyBlackwell; 2017. p. 97-109.

[97] Calvo SE, Clauser KR, Mootha VK. MitoCarta2.0: an updated inventory of mammalian mitochondrial proteins. Nucleic Acids Res. 2016;44(D1):D1251-D1257.

[98] Phung CD, Ezieme JA, Turrens JF. Hydrogen peroxide metabolism in skeletal muscle mitochondria. Arch Biochem Biophys. 1994;315(2):479-482.

[99] Radi R, Turrens JF, Chang LY, et al. Detection of catalase in rat heart mitochondria. J Biol Chem. 1991; 266(32):22028-22034.

[100] Fedorova M, Kuleva N, Hoffmann R. Identification, quantification, and functional aspects of skeletal muscle protein-carbonylation in vivo during acute oxidative stress. J Proteome Res. 2010;9(5): 2516-2526. 